\title{
Commentary
}

\section{COVID-19 and mental health}

\author{
Gitashree Dutta ${ }^{1}$, Tarun Kumar ${ }^{2 *}$ \\ ${ }^{1}$ Department of Community Medicine, NEIGRIHMS, Shillong, Meghalaya, India \\ ${ }^{2}$ Department of Pharmacology, AIIMS, Jodhpur, Rajasthan, India
}

Received: 15 June 2020

Accepted: 10 July 2020

*Correspondence:

Dr. Tarun Kumar,

E-mail: tarunkmr759@gmail.com

Copyright: (C) the author(s), publisher and licensee Medip Academy. This is an open-access article distributed under the terms of the Creative Commons Attribution Non-Commercial License, which permits unrestricted non-commercial use, distribution, and reproduction in any medium, provided the original work is properly cited.

\section{INTRODUCTION}

World Health Organization (WHO) considered the outbreak of a novel coronavirus, COVID-19, to be a Public Health Emergency of International Concern on January 2020 and finally on March 2020, WHO declared COVID-19 as a pandemic. ${ }^{1,2}$

Public health authorities around the globe are acting to contain the COVID-19 outbreak by recommending measures such as social distancing and quarantine; however, it lacks the emphasis and intervention of its impact on mental health. ${ }^{2}$ The COVID-19 infection is a new disease; hence it is important to understand that its emergence and spread may lead to cognitive distress, anxiety, and fear in the public which then may lead to harmful stereotypes. With rising public stigma, the affected individuals tend to hide their symptoms to avoid discrimination which may prevent them from seeking immediate healthcare intervention, thereby having a devastating outcome. ${ }^{3}$

People who are at risk include elderly population and people with chronic diseases, children and teens, frontline workers of COVID-19 like doctors, nurses, sanitation workers, police force, etc., workers in the unorganised sector, survivors of COVID and people who had mental health ailments from before. ${ }^{4}$

This article explains how COVID-19 pandemic has affected the mental health of different sections of population and also the role of social media in context of mental health and how to cope up with this pandemic by referencing various articles which are published worldwide.

\section{In the health professionals}

In light of the public health crisis of the on-going COVID-19 pandemic, it is highly important to acknowledge the psychological impact on healthcare professionals. During the COVID-19 outbreak, clinicians have been confronted with challenges which they have not been faced before like taking decisions regarding COVID related triaging, isolation in a very stressful situation and limited resources, since this is a novel virus for the whole medical fraternity to take it under consideration. The pressure to act timely and to successfully diagnose, isolate and treat especially amid intense public and media scrutiny is another factor. In addition, due to the increased risk of exposure to the virus, frontline workers like doctors, nurses and healthcare professionals fear that they may contract COVID-19 themselves and thus worrying about bringing the virus home and passing it on to their family members. The healthcare staff also report increased stress levels when dealing with unwilling and uncooperative patients who do not adhere to safety instructions, and feelings of helplessness when dealing with critically ill patients, in the context of limited resources. The experience of working with protective equipment for long periods which causes difficulties in breathing without any access to toilet and food results in subsequent physical and mental fatigue. ${ }^{5}$ These challenges are similar to almost all the countries which are affected with COVID-19 like Greece, Italy, China, India, etc. This phase of psychiatric morbidity for the Healthcare professionals dealing with COVID-19 are somewhat similar to the timings of the other pandemics like SARS, MERS and H1N1. ${ }^{6-8}$ A very recent study among healthcare professionals in a tertiary infectious disease hospital for COVID-19 in China, 
revealed a high incidence of anxiety and stress disorders among frontline medical staff. ${ }^{9}$

\section{In the general population}

The social and economic fissures exposed by the pandemic will result in mass unemployment, starvation, thereby increase in thefts and robberies, and also increase in gender-based violence, homelessness, alcoholism, loan defaults and finally poverty grasping thousands of people. These factors will in turn cause increase in chronic stress, anxiety, depression, alcohol dependence, and self-harm; leading to an overall rise in morbidity and the number of disability-adjusted life years linked to mental health. This COVID-19 pandemic will be causing a huge challenge in achieving the sustainable developmental goals.

Public health emergencies, in general, affect the health, safety, and wellbeing of both individuals (for example, insecurity, confusion, emotional isolation, and stigma) and communities (owing to economic loss, work and school closures, inadequate resources for medical response, and deficient distribution of necessities). These effects may translate into a range of emotional reactions (such as distress or psychiatric conditions), unhealthy behaviours (such as excessive substance use) specially in young age population and noncompliance with public health directives such as home confinement in people who contract the disease and in the general population. ${ }^{5}$

\section{IMPACT OF SOCIAL MEDIA ON MENTAL HEALTH}

A cross-sectional study among Chinese citizens aged 18 years old from 31 provinces and autonomous regions described the prevalence and distribution of anxiety and depression among Chinese population and examined their associations with social media exposure during COVID19 outbreak and found out higher prevalence of depression (48.3\%) and anxiety (22.6\%). ${ }^{10}$ These findings are consistent with the previous studies' that public health emergencies can cause public mental health problems, such as Wenchuan and Lushan earthquakes, 2014 Ebola outbreak, and SARS. ${ }^{11-14}$

This study also found that $82.0 \%$ of participants frequently expose them to social media, and frequently social media exposure associated high odds of anxiety. There may be two reasons explaining the association between social media exposure and mental health. During COVID-19 outbreak, disinformation and false reports like the forwarded WhatsApp messages about the COVID-19 have bombarded social media and stoked unfounded fears among many netizens, which may confuse people and harm people's mental health. ${ }^{15,16}$ Besides, many citizens expressed their negative feelings, such as fear, worry, nervous, anxiety, on social media, which can prove to be contagious to others.

\section{CONCLUSION}

India's investment in health including mental health needs a boost. Mental health should be treated as a public health crisis that needs long term fixation. Mental health interventions can increase the productivity of a nation and in turn cause an economic uplifting of the nation as a whole. Both news media and social media, text messages can be used to create and spread awareness to decrease the stigma against mental health and thereby increasing the health-seeking behaviour.

There is a good chance that different forms of addictions will raise after COVID-19 because human beings many a times resort to addictions to combat stress and depression. It will be beneficial to provide both physical and psychological rehabilitation services to the sufferers.

To reduce the pressure on the overburdened primary and secondary mental health task force, the focus should be on self, family, community and primary care. Group psychological support for the unemployed will help. Digitally-mediated therapy and tele-psychiatry should be scaled up.

Lastly, we should know how to take care of ourselves and our family during this time of crisis. We should not refrain from giving a comforting shoulder to our family and friends since this is a tough time for all of us. This is the time when we should be focusing on positive aspects of life, take healthy diet, get true facts from validated websites and refrain from forwarding any non-validated information through social media and in order to decrease the social media associated anxiety there should be monitoring and filtering out false information and promoting accurate information though cross-section collaborations.

\section{REFERENCES}

1. World Health Organization. Bulletin of the World Health Organization. Available at: https://www. who.int/bulletin/online_first/COVID-19/en/. Accessed on 14 June 2020.

2. Mental health and psychosocial considerations during the COVID-19 outbreak. Available at: https://www.who.int/docs/default-source/corona viruse/mental-health-considerations.pdf. Accessed on 14 June 2020.

3. Rajkumar RP. COVID-19 and mental health: A review of the existing literature. Asian J Psychiatr. 2020;52:1-4.

4. Mental health and coping during Covid-19. Available at: https://www.cdc.gov/coronavirus/ 2019-ncov/daily-life-coping/managing-stressanxiety.html. Accessed on 14 June 2020.

5. Shah K, Kamrai D, Mekala H, Mann B, Desai K, Patel RS. Focus on Mental Health During the Coronavirus (COVID-19) Pandemic: Applying 
Learnings from the Past Outbreaks. Cureus. 2020;12(3):1-8

6. Chong MY, Wang WC, Hsieh WC, Lee CY, Chiu NM, Yeh WC, et al. Psychological impact of severe acute respiratory syndrome on health workers in a tertiary hospital. Br J Psychiatr. 2004;185:127-33.

7. Brooks SK, Dunn R, Amlôt R, Rubin GJ and Greenberg N. A systematic, thematic review of social and occupational factors associated with psychological outcomes in healthcare employees during an infectious disease outbreak. J Occup Environ Med. 2018;60:248-57.

8. Lee SM, Kang WS, Cho AR, Kim T, Park JK. Psychological impact of the 2015 MERS outbreak on hospital workers and quarantined hemodialysis patients. Compr Psychiatr. 2018;87:123-7.

9. Huang JZ, Han MF, Luo TD, Ren AK, Zhou XP. Mental health survey of 230 medical staff in a tertiary infectious disease hospital for COVID-19. Zhonghua Lao Dong Wei Sheng Zhi Ye Bing Za Zhi. 2020;38(3):192-5.

10. Gao J, Zheng P, Jia Y, Chen H, Mao Y, Chen S, et al. Mental health problems and social media exposure during COVID-19outbreak. PLoS ONE. 2020;15(4):e0231924.

11. Xie Z, Xu J, Wu Z. Mental health problems among survivors in hard-hit areas of the 5.12 Wenchuan and 4.20 Lushan earthquakes. J Ment Health 2017;26(1):43-9.
12. Shultz JM, Baingana F, Neria Y. The 2014 Ebola Outbreak and Mental Health: Current Status and Recommended Response. JAMA. 2015;313(6):5678.

13. Ji D, Ji YJ, Duan XZ, Li WG, Sun ZQ, Song XA, et al. Prevalence of psychological symptoms among Ebola survivors and healthcare workers during the 2014-2015 Ebola outbreak in Sierra Leone: a crosssectional study. Oncotarget. 2017;8(8):12784-91.

14. Mak IW, Chu CM, Pan PC, Yiu MG, Chan VL. Long-term psychiatric morbidities among SARS survivors. Gen Hosp Psychiatr. 2009;31(4):318-26.

15. Xinhua. Bat soup, biolab, crazy numbers ... Misinformation "infodemic" on novel coronavirus exposed. Available at: http://www.xinhuanet.com/ english/2020-02/04/c_138755586.htm. Accessed on 12 June 2020.

16. Roth F, Bro“nnimann G. Focal Report 8: Risk Analysis Using the Internet for Public Risk Communication. Available at: https://www. researchgate.net/publication/256126259. Accessed on 14 June 2020.

Cite this article as: Dutta G, Kumar T. COVID-19 and mental health. Int J Community Med Public Health 2020;7:3309-11. 